\title{
IS THERE A CONSERVATIVE SOLUTION TO THE MANY THINKERS PROBLEM? ${ }^{1}$ David M. Kovacs
}

\author{
Forthcoming in Ratio, Vol. XXIII no 3 (September 2010)
}

\begin{abstract}
'On a widely shared assumption, our mental states supervene on our microphysical properties - that is, microphysical supervenience is true. When this thesis is combined with the apparent truism that human persons have proper parts, a grave difficulty arises: what prevents some of these proper parts from being themselves thinkers as well? How can I know that I am a human persons and not a smaller thinker enclosed in a human person? Most solutions to this puzzle make radical, if not absurd, claims. Recently, however, Michael Burke and Howard Robinson proposed conservative solutions that, according to them, do not have such undesired consequences. This paper argues that the conservative solutions tacitly assume at least one of the radical ones, and therefore they provide no alternative to the extreme solutions.'
\end{abstract}

The apparent truism that human persons have proper parts seems to lead to a paradox. ${ }^{2}$ It is true of at least some of our parts that we would count them as thinkers if they were not parts of a larger thinking being. But then, it is difficult to tell why they are not thinkers in their own right. It is certainly desirable to avoid this seeming consequence, for it would imply that we share our thoughts with a multitude of thinkers under our skin. Nonetheless, it has proved to be embarrassingly difficult not to draw this moral without sacrificing some very strong intuitions; most philosophers who want to preserve the 'one thinker to a place' principle are forced either to give up on the idea that consciousness is both an intrinsic and microphysically supervenient property, or to commit themselves to revisionary theories about composition or identity. Recently, however, Michael Burke (1997, 2003) and Howard Robinson (2006) have suggested that denying the existence of the many thinkers has none of these consequences, and offered moderate solutions to the problem. This paper argues that these solutions fail.

Section 1 generates the paradox as a consequence of nine independently plausible premises and differentiates it from similar metaphysical puzzles. Section 2 briefly surveys two current radical solutions on the market. It lies beyond the scope of this paper to argue for or against any of these solutions. Sections 3 and 4 examine Burke's and Robinson's conservative solutions respectively. I will argue that these solutions can remain coherent only at the cost of collapsing into some of the radical accounts. Again, it is not my goal to refute these accounts. Much of what Burke and Robinson say may very well be on the right track; they are just not alternatives to the old solutions - or so I shall argue.

\section{Articulating the problem}

Consider the following scenario: an ordinary human person John loses his left index finger at time $t_{1}$. The resulting entity at a later time $t_{2}$ consists of the parts that composed John at $t_{1}$ save the parts of the left index finger; call this resulting entity Little John. (It seems highly

\footnotetext{
${ }^{1}$ Penultimate draft; please do not cite without permission.

${ }^{2} y$ is a proper part of $x$ iff every part of $y$ is also a part of $x$ but not vice versa. Unlike the more widespread definition according to which $y$ is a proper part of $x$ iff $y$ is a part of $x$ but is not identical to $x$, this one does not beg the question against relative identity. A relative identity theorist may want to say that a thing and its proper part can be identical under some sortal (this is why premise (9) will not be redundant in section 1.)
} 
plausible that John persists as Little John, but this need not be presupposed to generate the paradox.) John had numerous macroscopic parts at $\mathrm{t}_{1}$ : head, left leg, right arm, heart etc. He also had some parts for which we have no name, like the one consisting of all and only the parts of John, save his left index finger, as he was at $t_{1}$ - his left index finger complement, to use a widespread technical term. Call this almost John-sized entity John Minus. ${ }^{3}$

John Minus at $t_{1}$ consists of all and only the parts that make up Little John at $t_{2}$. Furthermore, these parts are arranged in the same way in John Minus and in Little John. Perhaps this cannot be carried out on the current level technology; as a result of the mutilation, Little John will have a wound on his hand that John Minus did not. But this difference seems irrelevant, so let me stipulate that John Minus and Little John are microphysically identical.

In that case, we face a problem. Little John is obviously conscious; some people are known to have consciously undergone the loss of their fingers. But if Little John is conscious, then John Minus ought to be conscious as well. He is qualitatively identical to Little John down to the last particle, and if consciousness supervenes on the microphysical, then any duplicate of a conscious thing is also conscious. But John Minus cannot be conscious, for he is part of something, namely John, that is also conscious. It would be absurd to hold that there is a plethora of conscious beings where we thought there was only one. Thus we are confronted with the paradox that has come to be known as the Many Thinkers Problem. For ease of exposition, I formulate the paradox as a consequence of nine independently plausible assumptions ${ }^{4}$ :

(1) John exists

(2) John is conscious

(3) John Minus (a large proper part of John) exists

(4) Little John exists

(5) Little John is conscious

(6) Little John is microphysically identical to John Minus

(7) Consciousness is an intrinsic property

(8) Intrinsic properties are nomically supervenient on microphysical properties

From (1)-(8): (C1) John Minus is conscious

(9) John is not identical to John Minus

From (C1) and (9): (C2) There are at least two thinkers where John is

Because there are infinitely many large parts of John akin to John Minus (like John's right thumb complement, his left ear complement etc.), the argument generalizes to

\footnotetext{
${ }^{3}$ To keep things simple, I will work with the three-dimensionalist version of the puzzle and will presuppose a temporally indexed theory of parthood. As we shall immediately see, these assumptions are metaphysically innocuous, since the Many Thinkers problem (unlike Geach's similar problem of the 1001 cats) is not a problem about persistence. With little effort, the paradox could be rephrased in terms of spatiotemporal parts.

${ }^{4}$ From now on - again, for the sake of simplicity - I will omit the time-indices. Throughout the whole paper, 'John Minus' will name an entity at $t_{1}$ and 'Little John' an entity at $t_{2}$. As already indicated, I wish to leave it open whether John persists as Little John at $t_{2}$.
} 
(C3) There are many thinkers where John is

I find all the premises quite plausible, and I assume that other people are not very different from me in this regard. Partly for this reason, and partly for the sake of clarity I am going to use the terms 'radical' and 'conservative' in a somewhat stipulative manner: solutions that embrace the conclusion or reject at least one of the premises (or their modified versions - see subsection 4.1) will be counted as radical, while solutions that deny that the conclusion follows I will call conservative.

A note is in order here. Although the problem presented above bears some superficial resemblance to more familiar metaphysical puzzles, it is not to be confused with them. First, the Many Thinkers Problem is obviously not the same as Unger's Problem of the Many, a paradox about how to determine the boundaries of a physical object if there are many particles in its vicinity that are neither determinately parts of, nor determinately not parts of the object in question (Unger 1980). Apparently, we do not only not know what those boundaries are, but we also have to subscribe to a multitude of overlapping objects with slightly different composing matter. However, the Many Thinkers Problem has nothing to do with vagueness and indeterminacy: we would face it even if all objects had perfectly sharp boundaries. Second, the puzzle has to be distinguished from problems resulting from spatiotemporally coincident thinking objects belonging to different sorts but composed by the same matter (Olson 2003). The Many Thinkers Problem has nothing to do with sorts and is faced by any sane materialist ontology of human persons. Third, the problem is not the same as Geach's Problem of the 1001 Cats (Geach 1980: 215). That is a problem about the identity conditions and modal fragility of material objects. The worry posed by the Many Thinkers Problem is of a different kind: it is not about whether either of John and John Minus survive John's mutilation. It is about whether John Minus was a thinker before the mutilation.

That being said, some of the available solutions to the Many Thinkers Problem are familiar from the literature on the aforementioned topics. This is because although these problems are not the same, they are disturbing for similar reasons: in spite of how desperately we want to avoid thinking beings that are coincident or to a great extent overlapping with us, their existence seems to be an inescapable consequence of some of our very ordinary beliefs. No wonder that some of their solutions also apply to the Many Thinkers Problem.

\section{Microphysical supervenience and intrinsicness}

In order to find a way out of this paradox, either at least one of the premises has to be rejected, or it must be shown that they do not entail the embarrassing conclusion. Since the goal of this paper is not to assess the radical solutions but to find out whether they have existing alternatives, I will not go into details about them. It is enough for the reader of this paper to know that they all deny at least one of the premises. ${ }^{5}$ However, I will make an exception for those solutions that deny either premise (7) or (8). Advocates of these solutions

\footnotetext{
${ }^{5}$ There are at least two ways to reject (4): compositional nihilists like Unger (1980) and Dorr and Rosen (2002) deny that there are composite material objects, while Chisholm (1976) seriously considers (but does not straightforwardly endorse) the option that persons are elementary particles. Some philosophers (van Inwagen 1981; Olson 1995) reject the existence of 'arbitrary undetached parts' and, as a result, premise (3). 'Minimalists' who identify persons with brains (Hudson 2001: Ch. 4, 2007; Dainton 2008: 227-235) reject premise (2). Relative identity theorists like Geach (1980) claim that, since identity is a sortal-relative concept, premise (9) is in an important sense false. And last but not least, Lewis (1999) simply accepts the conclusion and argues that since we do not count persons by strict numerical identity, we ought to learn to live with the many thinkers.
} 
argue that consciousness is not an intrinsic property or that intrinsic properties do not supervene on the microphysical. What justifies this special treatment is that my main argument against Robinson's account will trade upon the claim that he cannot consistently keep both premises.

What is the exact claim in question? Trenton Merricks (1998) urges that because we have good reasons to accept the other premises, we ought to reject the following supervenience thesis in order to avoid the many thinkers:

Microphysical Supervenience (MicSup): Necessarily, if atoms $A_{1}$ through $A_{n}$ compose an object that exemplifies intrinsic qualitative properties $Q_{1}$ through $Q_{n}$ then atoms like $A_{1}$ through $A_{n}$ (in all their respective intrinsic qualitative properties), related to one another by all the same restricted atom-to-atom relations as $A_{1}$ through $A_{n}$, compose an object that exemplifies $\mathrm{Q}_{1}$ through $\mathrm{Q}_{\mathrm{n}}$. (Merricks 1998: 59)

Once MicSup is denied, we can consistently say that John is conscious but John Minus is not. Although Little John is conscious and he does not differ in his microphysical properties from John Minus, it does not follow that John Minus is also conscious. Consciousness does not supervene on the microphysical, so they can differ in this important respect even if they do not differ in their microphysical properties.

Some philosophers, however, arrived at the contrary conclusion: since we have all reasons to stick to MicSup, we would better say that the property of being conscious is not an instance of it, for consciousness is extrinsic - that is, premise (7) is false.

While there are many possible definitions of 'intrinsic', it seems fair to use the one that has been endorsed by a main advocate of the extrinsicness solution. Theodore Sider (2001) adopts this definition of intrinsicness from David Lewis: let us call any two objects duplicates iff all their parts have the same natural properties and stand in the same natural relations to each other. A property is intrinsic iff it can never differ between any pair of possible duplicates, whether in the same or different possible worlds. ${ }^{6}$

Not every possible duplicate of Little John is conscious; for example, John Minus is arguably not. Therefore, consciousness is not an intrinsic property on Lewis's account. According to Sider, being conscious is one of those extrinsic properties that are also maximal. Roughly, a property F is maximal iff large parts of an F cannot themselves be Fs (Sider 2001, 2003). For instance, being a house is a maximal property: the window-complement in my house fails to be a house because it is a proper part of something that is a house. Similarly, being conscious is also a maximal property: although John Minus has everything intrinsically required to be conscious (he is conscious* in Sider's terminology), he fails to be conscious precisely because he is part of something larger that is also conscious. By this reasoning, maximality theorists can preserve the idea of microphysical supervenience by rejecting premise (7).

\section{Burke's solution}

Without argument, I assume that none of the above solutions is very appealing. Both premise (7) and (8) have strong intuitive force. Could we do better? Some philosophers say we could.

\footnotetext{
${ }^{6}$ Lewis (1986: 59-69). 'Natural' is an undefined primitive in Lewis's account. This is often taken to be rather a virtue than a vice, for it makes the account neutral with respect to which properties are natural.
} 
Michael Burke and Howard Robinson advocate conservative solutions that seem not to commit them to curious metaphysical theses. ${ }^{7}$ Their accounts are different in important respects, but both aim to resolve the paradox without sacrificing significant intuitions. Put more formally, they believe that all the premises (1)-(9) are true but (C3) does not follow from them, because the word 'conscious' occurs equivocally in the argument.

\subsection{Burkean conservativism}

Burke, just like Sider, appeals to the notion of maximality, but he does not bind it to extrinsicness. $^{8}$ Instead he argues that there are important respects in which John and John Minus are different - important enough that they account for the fact that John Minus is not conscious in any significant sense. The most important differences for the present discussion are these:

1. John's self-referential statements refer to John, but John Minus's do not refer to John Minus. If John Minus is conscious, then he is systematically wrong about the referent of his Istatements.

2. If John Minus is conscious, then he is immediately aware of some sensations occurring outside his body. On the other hand, John is aware of sensations only in the ordinary way. Similarly, if John Minus is conscious, then he has direct and voluntary control over some parts which do not belong to him. Another related fact about John is that he has differential concern for John over John Minus. But then, because he has the very same mental states, John Minus also has differential concern for John over himself.

3. The attribution of mental states helps predict John's behaviour. On the other hand, attributing mental states to John Minus does not enhance our ability to predict John Minus's behaviour. At best, it would help predict someone else's (John's) behaviour.

These reasons tell against attributing consciousness to proper parts of John. Their behaviour is not coherent and rational enough to make it explanatorily fruitful to attribute conscious states to them. However, Burke adds that although John is conscious and John Minus is not, this is not to be understood as a huge difference that needs much explanation. John Minus is not conscious, but that does not mean that he is devoid of consciousness: there is consciousness in him. While John is a genuine subject, John Minus is a mere container of consciousness, but he is not conscious. So there is only one thinker in the story, John.

\subsection{The trouble with Burke's account}

On the face of it, Burke's solution is plausible and elegant: only John is a person, and his parts are mere thought-containers. This is how we ordinarily treat human persons and their proper parts. On reflection, however, the question still presses itself: What makes John Minus incapable of undergoing the mental states he contains? Why is he not an experiencer? If being a subject of consciousness means anything more than merely containing it, this distinction ought to be explained. And recall, Little John is microphysically identical to John Minus.

\footnotetext{
${ }^{7}$ Robinson is a Berkelyan idealist and thus denies (8), so he does not in fact endorse the view. Instead he offers it for materialist philosophers as a possible solution to various puzzles about coincident and overlapping thinkers (see his 2006: 255-8).

${ }^{8}$ In his 1997, Burke is not explicit about whether it follows from the fact that personhood is a maximal concept that consciousness is not intrinsic. However, in his 2003 (123, footnote 10) it becomes clear that he wishes to defend his account without conceding that consciousness is an extrinsic property.
} 
It will not do to argue that because of the reasons laid down in 1-3., we should not attribute conscious states to John Minus. We know from the beginning that the attribution of conscious states to him leads to absurdities. But in section 1, an argument has been presented to the effect that in spite of all that, John Minus is conscious. Merely pointing out some of its further odd consequences does not refute this argument. Which premise is false? If none, why should we believe that the conclusion does not follow? Burke does not say.

So the question remains: why is John Minus only a container of consciousness? What makes him incapable of undergoing the states it contains? Either being a subject is intrinsic, or it is not. If it is not, then Burke's account denies premise (7). It is hard to see how consciousness could be intrinsic if the property of being a subject is not. And if it is intrinsic, then there will be a difference between Little John and John Minus that is not microphysically underpinned - that is, the theory turns out to deny premise (8). Hence, Burke's account is either wrong or not conservative.

\section{Robinson's offer}

In veins similar to Burke's distinction between subjects and containers, Robinson draws the line between having thoughts and merely hosting them. This position is notably different from Burke's, taking into consideration Robinson's analogy with the relation between hardwares and computer programs: persons are related to their bodies as softwares are to their underlying hardwares. According to the view on offer, neither the object we initially identified with John nor any of its proper parts is a thinker. Although a person is wholly physical, it is not a physical object but a physical process, constituted by (but not identical to) a series of mental states.

Here is how Robinson's account - or the Process View, as I am going to refer to it - is supposed to solve the Many Thinkers Problem. While the part-whole relationship between John Minus and John turned out to be the source of embarrassing puzzles, the relation between the corresponding processes is quite unproblematic. John and John Minus have the same mental properties, so they are the same process. That is, by the John Minus process and by the John process we simply pick up the same person. The paradox disappears.

One might think that this solution itself is radical enough. If persons are not objects but processes, then there are many things that cannot really happen to them. To begin with, persons cannot change their properties. While it involves changes, a process itself cannot change. Neither do persons have ordinary physical properties such as height and weight. Attributing properties like that to processes would be a category mistake. To sum up, even if the process talk did save all of our initial intuitions, it would probably threat some other ones. However, this is not my main worry.

\subsection{Problems with the Process View}

I am afraid that Robinson's solution is not immune from the problems which beset the old ones. The part-whole puzzle about objects can be rephrased in terms of processes. Apparently there is nothing that precludes processes from having shorter subprocesses. For instance, let us assume that John, a person consisting of mental states $\mathrm{S}_{1}, \ldots, \mathrm{S}_{\mathrm{n}}$, comes into existence at time $t_{0}$ and terminates at $t_{n}$. Processes are not indivisible: he has a subprocess consisting of states $\mathrm{S}_{1}, \ldots, \mathrm{S}_{\mathrm{n}-1}$ that spans from $\mathrm{t}_{0}$ to $\mathrm{t}_{\mathrm{n}-1}$ (call it Short John), and this subprocess has everything intrinsically required to be conscious. Short John, however, cannot be identified with John, simply because they differ in their properties; Short John lasts shorter. Now, John could have 
been instantaneously annihilated just at the moment at which Short John terminates - let us call this short-living counterpart Dying John. ${ }^{9}$ In the counterfactual case, Dying John would surely be conscious. But Short John is not, or at least this is what we are inclined to say. What grounds the difference?

Before proceeding, let me first state the modified premises in lines with the Process View:

(1') Series $S_{1}, \ldots, S_{n}$ constitutes a thinker

(2') The thinker constituted by series $S_{1}, \ldots, S_{n}$ is conscious

(3’) Series $\mathrm{S}_{1}, \ldots, \mathrm{S}_{\mathrm{n}-1}$ exists

(4') Series $S_{1}, \ldots, S_{n-1}$ would constitute a person if it were not succeeded by $S_{n}$

(5') The person that series $S_{1}, \ldots, S_{n-1}$ would constitute would be conscious

(6') If series $S_{1}, \ldots, S_{n-1}$ constituted a person, this series would be microphysically indistinguishable from series $\mathrm{S}_{1}, \ldots, \mathrm{S}_{\mathrm{n}-1}$ as it actually is

(7') Consciousness is an intrinsic property

(8') Intrinsic properties are nomically supervenient on microphysical properties

(9') Series $S_{1}, \ldots, S_{n-1}$ is not identical with series $S_{1}, \ldots, S_{n}$

Therefore,

(C') There are at least two thinkers where John is.

Robinson seeks to avoid C' by claiming that from its negligible microphysical difference with $S_{1}, \ldots, S_{n}$ it does not follows that series $S_{1}, \ldots, S_{n-1}$ also constitutes a thinker: at best, it constitutes a host. Hosts are not thinkers, so the problem goes away.

But this is not much of an improvement. For Robinson has nothing to say about why is Short John only a host and not a thinker. At this point, we seem to be left with the old solutions, or their relevantly modified versions: either Dying John mentally differs from Short John despite their microphysical identity because microphysical supervenience is false, or consciousness is not an intrinsic property and as such should not be expected to supervene on the microphysical. Either way, the distinction between process hosts and process subjects will not stand without the rejection of at least one of the (modified) premises (1')-(9').

\subsection{A reply: the liberal concept of constitution}

As we have seen, the spatial problem of the many thinkers reappears as a temporal one for the Process View. Something must account for the fact that $S_{1}, \ldots, S_{n-1}$ constitutes a thinker but $\mathrm{S}_{1}, \ldots, \mathrm{S}_{\mathrm{n}-1}$ constitutes only a host. But we do not want to deny any of premises (1')-(9'). How could the Process View be saved?

In discussion, Robinson argued that in order to avoid the many thinkers, the process theorist is not compelled to deny any of the premises. It can be conceded that series $\mathrm{S}_{1}, \ldots, \mathrm{S}_{\mathrm{n}-1}$ constitutes a thinker even if it is succeeded by $S_{n}$; it merely has to be added that this thinker is

\footnotetext{
${ }^{9}$ The term 'counterpart' is intended to be neutral here, and is just a loose and convenient way of expressing that there could have been a being like Dying John. I am not concerned with whether John could have been Dying John, and if so, whether the relation between them would be strict identity or counterpart relation. We have earlier seen that the Many Thinkers problem is not one about persistence; now it can be added that it is not a problem about identity across possible worlds either. (However, this modified version is a problem about the persistence of processes. While there is a lively debate between three- and four-dimensionalist accounts of the persistence of objects, I take the view that processes are temporally extended and have temporal parts to be fairly uncontroversial.)
} 
simply John, who also has $S_{n}$. To ensure that there be a thinker who is more short-lived than John it would be required that there be a series $S_{1}, \ldots, S_{n-1}$ which constitutes a thinker that has no mental states other than $S_{1}, \ldots, S_{n-1}$ (from now on, I will call this relation 'exhaustive constitution'). However, this is a concession Robinson is not forced to make.

This is the point where, in my opinion, the Process View showcases its main advantages over the other views. The object theorist cannot make this move, for composition is an exhaustive concept: the locution 'the $x$ s compose object $O$ ' implies that, if all the $x$ s are atomic, there is no part $y$ such that $y$ is part of $\mathrm{O}$ but has none of the $x \mathrm{~s}$ as parts. This does not hold for mental states: mental states can constitute a thinker without exhaustively constituting it. This way Robinson can avoid the process version of the Many Thinkers Problem; from premises (1')-(8') it does not follow that any series not having $S_{n}$ is conscious, which makes (9') harmless too. Such an inference would be invalid, because on the Process View persons are not identical with series of mental states but are only constituted by them, whatever this exactly means. Since constitution need not be exhaustive, there is nothing wrong with the idea that series $\mathrm{S}_{1}, \ldots, \mathrm{S}_{\mathrm{n}-1}$ constitutes a person - it constitutes John himself. If the Process Theorist is allowed to make use of this liberal, non-exhaustive understanding of constitution, she seems to have provided a conservative solution to the Many Thinkers Problem.

\subsection{Why the liberal conception does not solve the problem}

However promising this proposal may seem at first sight, it cannot stand as it was stated above. Let me start with the - presumably uncontroversial - claim that process persons still ought to satisfy a supervenience principle analogous to MicSup, something like the following:

Microphysical Supervenience for Processes (MicPro): Necessarily, if states $S_{1}$ through $S_{n}$ constitute a process that exemplifies intrinsic qualitative properties $Q_{1}$ through $Q_{n}$, then states like $S_{l}$ through $S_{n}$ (in all their respective intrinsic qualitative properties), related to one another by all the same restricted state-to-state relations as $S_{1}$ through $S_{n}$, constitute a process that exemplifies $\mathrm{Q}_{1}$ through $\mathrm{Q}_{\mathrm{n}}$.

Now, whereas the object theorist cannot say that John is the only person composed by $A_{1}$ through $A_{n-1}$, Robinson can say that it is John (the process) that is constituted by $S_{1}$ through $\mathrm{S}_{\mathrm{n}-1}$ (although he is not constituted only by them). Unfortunately, closer examination reveals that MicPro implies that John does not have the same intrinsic qualitative properties as Dying John.

How can we show this? One might think that the prospects of the anti-Robinsonian are quite dim. For suppose that Dying John is constituted by states $S_{1}, \ldots, S_{n-1}$ and exemplifies properties $\mathrm{Q}_{1}, \ldots, \mathrm{Q}_{\mathrm{n}-1}$. Presumably, if John can be constituted by states $\mathrm{S}_{1}, \ldots, \mathrm{S}_{\mathrm{n}-1}$ without being constituted only by them, then nothing precludes him of having properties $\mathrm{Q}_{1}, \ldots, \mathrm{Q}_{\mathrm{n}-1}$ while also having some other properties. Thus John and its temporal parts seem to confine to MicPro. No problem so far.

At this point, however, Robinson's main weapon can be turned against himself. Let us assume that John is constituted by states $\mathrm{S}_{1}, \ldots, \mathrm{S}_{\mathrm{n}-1}$ (sic!) and has intrinsic qualitative properties $\mathrm{Q}_{1}, \ldots, \mathrm{Q}_{\mathrm{n}}{ }^{10}{ }^{10}$ However, Dying John is also constituted by $\mathrm{S}_{1}, \ldots, \mathrm{S}_{\mathrm{n}-1}$, though he has no

\footnotetext{
${ }^{10}$ Since Robinson takes 'being constituted by certain states' to be a non-exhaustive relation, it is correct to say that John, who also has $S_{n}$, is constituted by $S_{1}, \ldots, S_{n-1}$. This is perfectly compatible with his also being constituted by $S_{1}, \ldots, S_{n}$.
} 
further states. The worry is that Dying John does not exemplify properties $\mathrm{Q}_{1}, \ldots, \mathrm{Q}_{\mathrm{n}}$, for some of these properties are supervenient upon states of John that Dying John does not have. So there is a case to which MicPro does not apply, which commits Robinson to a rejection of the process version of microphysical supervenience. This makes the account radical.

Robinson might resort to a weaker supervenience thesis that is not violated by denying that the series $S_{1}, \ldots, S_{n-1}$ exhaustively constitutes a thinker. Such a thesis would hold something like this:

\begin{abstract}
Weak Supervenience of Processes (WeakPro): Necessarily, if states $S_{1}$ through $\mathrm{S}_{\mathrm{n}}$ exhaustively constitute a process that exemplifies intrinsic qualitative properties $Q_{1}$ through $Q_{n}$, then series like $S_{1}$ through $S_{n}$ (in all their respective intrinsic qualitative properties), related to one another by all the same restricted state-to-state relations as $S_{1}$ through $S_{n}$, constitute a process that exemplifies $\mathrm{Q}_{1}$ through $\mathrm{Q}_{\mathrm{n}}$.
\end{abstract}

The word 'exhaustively' in the antecedent makes WeakPro immune to John / Dying Johnstyle counterexamples. Although series $S_{1}, \ldots, S_{n-1}$ does constitute John, from this we cannot infer that Dying John exemplifies the same intrinsic qualitative properties because series $\mathrm{S}_{1}, \ldots, \mathrm{S}_{\mathrm{n}-1}$ does not exhaustively constitute John. On the other hand, these states exhaustively constitute Dying John, and it is valid to infer from this that John has all the intrinsic qualitative properties that Dying John has.

However, this supervenience thesis is odd, if not incoherent. According to WeakPro, a thinker's qualitative intrinsic properties supervene on its states only if those states exhaustively constitute the thinker. But constituting a thinker exhaustively is a patently extrinsic property of those states: it depends on whether they are followed by some further states. How could intrinsic properties of states supervene on such extrinsic features as their being succeeded by other states? Whether some property supervenes on certain states ought not to depend on the presence of other states. ${ }^{11}$ Of course this rule applies only to intrinsic properties, but being a thinker - unless Robinson is willing to reject premise (7’), which would make his account radical again - is surely to be treated as intrinsic.

The process theorist may reply that from the fact that a property $\mathrm{P}$ supervenes on an extrinsic property $\mathrm{Q}$ it does not follow that $\mathrm{P}$ itself is also extrinsic. For instance, being male supervenes on having an Y chromosome and being at least $3000 \mathrm{~km}$ far from the North Pole. Technically speaking, it really does: it is true that when there is difference in maleness, there must be a difference in having an Y chromosome and being at least $3000 \mathrm{~km}$ far from the North Pole. Yet the subvenient property is clearly gerrymandered and extrinsic, while maleness is arguably intrinsic. So, Robinson could argue, the conclusion that he is committed to the extrinsicness of thinkerhood due to taking 'being exhaustively constituted...' as the subvenient base is rather hasty.

This objection has no grip on my argument. Whenever a property Q supervenes on property $\mathrm{P}$, it trivially supervenes also on any conjunctive property that has $\mathrm{P}$ as a conjunct. In such cases, however, the conjunctions could be pared down to their necessary conjuncts in order to get the minimal supervenience basis. But I know of no other way in which intrinsic properties could supervene on extrinsic properties, and this method will certainly not work for being exhaustively constituted. 'Being exhaustively constituted' is equivalent to 'being

\footnotetext{
${ }^{11}$ This does not contradict any kind of holism about the mental. If a mental state is partly determined by other mental states, it simply follows that it does not supervene on the subject's intrinsic qualitative features at a certain time.
} 
constituted and not followed by'. And although 'being constituted' is intrinsic, it has already been shown to be insufficient as the subvenient base for being a thinker. This shows that thinkerhood comes out as extrinsic, in the end.

The moral of this section is the following. If Robinson's account is correct, MicPro cannot be true because Little John and John satisfy its antecedent without satisfying its consequent. And the weaker WeakPro poses an intractable dilemma: either the principle has the absurd consequence that some intrinsic properties of a process supervene on its extrinsic properties, or it classifies thinkerhood as an extrinsic property - a consequence Robinson cannot afford if he wants his solution to remain conservative. I conclude that the Process View offers no alternative to the radical views.

\section{Conclusion}

While it would be nice to have a conservative solution to the Many Thinkers Problem, nobody to date has offered a convincing one. Burke's and Robinson's solutions depend on unclarified claims, and once they are worked out in detail, they are bound to collapse into the radical ones. It is illegitimate for Burke to distinguish between thinkers and thought containers unless he wants to deny either the intrinsicness of consciousness or the supervenience of intrinsic properties on the microphysical. Robinson's process-based solution is not better off either: it can account for not regarding temporal parts of person-processes also persons only at the cost of rejecting at least one powerful intuition. He could avoid this problem by resorting to a more liberal understanding of constitution. In that case, however, he faces a dilemma: either he must admit that consciousness violates any plausible thesis of microphysical supervenience, or he has to accept a weaker thesis that compels him to treat 'being conscious' as extrinsic. The upshot is that Burke's and Robinson's solutions offer no alternative to the extreme ones but presuppose some of them. ${ }^{12}$

Erasmus College,

1387 Budapest, P.O. Box 21

Hungary

davidm.kovacs@yahoo.com

\section{References}

Burke, Michael B. (1997): Persons and Bodies: How to Avoid the New Dualism. American Philosophical Quarterly, 34: 457-67.

Burke, Michael B. (2003): Is My Head a Person? In: Klaus Petrus (ed.): On Human Persons, pp. 107-125. Frankfurt, Ontos

Chisholm, Roderick (1976): Person and Object. Chicago and La Salle: Open Court

Dainton, Barry (2008): The Phenomenal Self. Oxford, Oxford University Press

Dorr, Cian and Gideon Rosen (2002): Composition as a Fiction. In: Richard M. Gale (ed.): The Blackwell Guide to Metaphysics, pp. 151-74. Blackwell, Oxford.

Geach, Peter (1980): Reference and Generality (3rd edition). Ithaca, Cornell University Press

Hudson, Hud (2001): A Materialist Metaphysics of the Human Person. Ithaca, Cornell University Press

\footnotetext{
${ }^{12}$ For comments and criticism, many thanks to Krisztina Orban, Orsolya Reich, Sven Walter, an anonymous referee, and audiences in Budapest and Osnabrück. I am especially indebted to Howard Robinson, who provided extensive and very helpful comments on numerous versions of this paper.
} 
Hudson, Hud (2007): I Am Not an Animal! In: Peter van Inwagen \& Dean W. Zimmerman (eds.): Persons: Human and Divine, pp. 216-34. Oxford, Oxford University Press

Langton, Rae \& David Lewis (1998): Defining 'Intrinsic'. Philosophy and Phenomenological Research, 58: 333-45.

Lewis, David (1986): On the Plurality of Worlds. Oxford, Oxford University Press

Lewis, David (1999): Many, but almost One. In: Papers on Metaphysics and Epistemology, pp. 164-82. Cambridge, Cambridge University Press

Merricks, Trenton (1998): Against the Doctrine of Microphysical Supervenience. Mind, 107: 59-71.

Merricks, Trenton (2003): Maximality and Consciousness*. Philosophy and Phenomenological Research, 61: 150-7.

Olson, Eric (1995): Why I Have No Hands. Theoria, 61: 182-97.

Olson, Eric (2003): An Argument for Animalism. In: John Barresi and Raymond Martin (eds.): Personal Identity, pp. 318-34. Oxford: Blackwell

Robinson, Howard (2006): Personal Identity, the Self and Time. In: Alexander Batthyany and Avshalom Elitzur (eds.): Mind and its Place in Nature. Frankfurt, Ontos

Sider, Theodore (2001): Maximality and Intrinsic Properties. Philosophy and Phenomenological Research, 63: 357-64.

Sider, Theodore (2003): Maximality and Microphysical Supervenience. Philosophy and Phenomenological Research, 66: 139-49.

Unger, Peter (1980): The Problem of the Many. Midwest Studies in Philosophy, 5: 411-67.

van Inwagen, Peter (1981): The Doctrine of Arbitrary Undetached Parts. Pacific Philosophical Quarterly, 62:123-37. 